Manuscript Number: JASC17-6R1

Title: Spatial thinking in archaeology: is GIS the answer?

Article Type: SI: Archaeological GIS

Keywords: Spatial thinking; GIS; Archaeology; Concepts of Space; Tools of Representation; Processes of Reasoning

Corresponding Author: Professor Gary Lock,

Corresponding Author's Institution: University of Oxford

First Author: Gary Lock

Order of Authors: Gary Lock; John Pouncett

Abstract: Being human embodies understandings of space and spatial relationships which are embedded within the material world and are underpinned by complex frameworks of knowledge and experience. Just as this applied to people living in the past, so it applies to those of us concerned with trying to understand those past lives through the archaeological record. Most, if not all, archaeological material has a spatial component and it is not surprising, therefore, that spatial thinking has been central within archaeological endeavour since the beginnings of the discipline. Specific forms of spatial thinking have changed with developing theory and methods and with changing analytical and technological opportunities resulting in the rich variety of approaches available to us today. Within this development, the rapid adoption of Geographic Information Systems (GIS) technology since the early 1990s has had a major impact on archaeology and related disciplines and its use is now almost taken for granted.

Although the use of GIS in archaeology has always been, and still is contentious at the theoretical level, the attractions of the technology are usually seen to outweigh any restrictions or disadvantages. In this paper we situate the use of GIS, including the papers in this volume, within the wider arena of spatial thinking in archaeology in an attempt to assess the impact that this technology has had on how we think spatially. 
Highlights (for review)

Spatial thinking in Archaeology: is GIS the answer.

Gary Lock and John Pouncett.

Highlights.

- A critique of spatial thinking in archaeology

- A critique of the development and current use of GIS in archaeology

- Combining the two to assess the current state of the sub-discipline 
Highlights (for review)

Manuscript has been uploaded with page numbers and line numbers.

Manuscript has been uploaded with page numbers and line numbers.

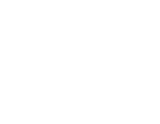

(1)

(1)

(1)

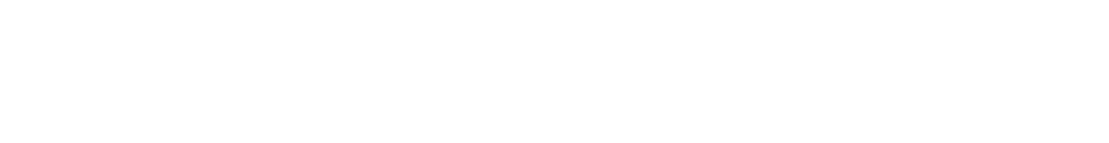

(1)

(1)

(1)

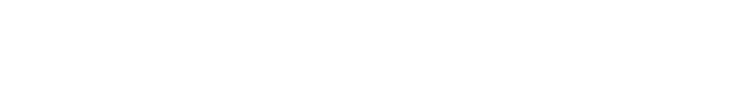

(1)

$\sqrt{3}$

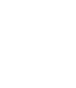

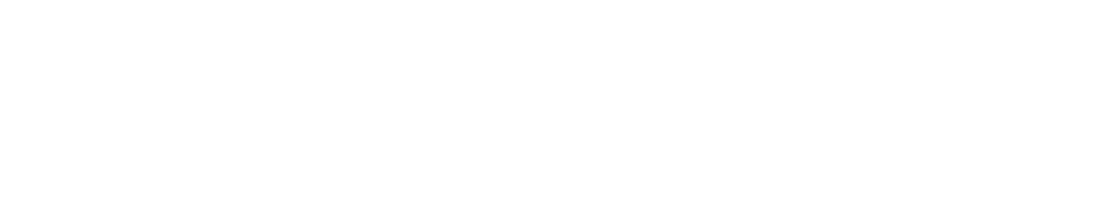





\title{
Spatial thinking in archaeology: is GIS the answer?
}

\author{
Gary Lock and John Pouncett \\ Institute of Archaeology \\ University of Oxford \\ 36, Beaumont Street \\ Oxford \\ OX1 2PG \\ UK 10
}

\begin{abstract}
Being human embodies understandings of space and spatial relationships which are embedded within the material world and are underpinned by complex frameworks of knowledge and experience. Just as this applied to people living in the past, so it applies to those of us concerned with trying to understand those past lives through the archaeological record. Most, if not all, archaeological material has a spatial component and it is not surprising, therefore, that spatial thinking has been central within archaeological endeavour since the beginnings of the discipline. Specific forms of spatial thinking have changed with developing theory and methods and with changing analytical and technological opportunities resulting in the rich variety of approaches available to us today. Within this development, the rapid adoption of Geographic Information Systems (GIS) technology since the early 1990s has had a major impact on archaeology and related disciplines and its use is now almost taken for granted. Although the use of GIS in archaeology has always been, and still is contentious at the theoretical level, the attractions of the technology are usually seen to outweigh any restrictions or disadvantages. In this paper we situate the use of GIS, including the papers in this volume, within the wider arena of spatial thinking in archaeology inan attempt to assess the impact that this technology has had on how we think spatially.
\end{abstract}

Keywords

Spatial thinking; GIS; Archaeology; Concepts of Space; Tools of Representation; Processes of Reasoning

\section{A Framework for Spatial Thinking}

It is important to define what we mean by 'spatial thinking' and we use the ideas detailed within Learning to Think Spatially (The US National Academies, 2006), a publication primarily focused on school children but with wider relevance. Spatial thinking is underpinned by spatial intelligence, one of seven different aspects of overall intelligence which varies between individuals.

Someone who has a developed spatial intelligence displays the following characteristics: 39

1. 'They have the habit of mind of thinking spatially: they know where, when, how and whyto think spatially.

2. They practice spatial thinking in an informed way: they have a broad and deep knowledge of spatial concepts and spatial representations, a command over spatial reasoning using a variety of spatial ways of thinking and acting, and well-developed spatial capabilities for using supporting tools and technologies.

3. They adopt a critical stance to spatial thinking: they can evaluate the quality of spatial data based on its source and its likely accuracy and reliability; can use spatial data to construct, articulate, and defend a line of reasoning or point of view in solving problems and answering questions; and can evaluate the validity of arguments based on spatial information.'

(ibid. 20) 
The implications of this for archaeology are interesting, firstly that spatial thinking is something that has to be learnt, developed and supported and secondly that the use of spatial methods, techniques and technologies does not make the user a spatial thinker. Thinking spatially entails knowing about (ibid. 12):

1. Concepts of space: providing the conceptual and analytical framework within which data can be integrated, related and structured into a whole.

2. Tools of representation: providing the forms within which structured information can be stored, analysed, comprehended and communicated.

3. Processes of reasoning: providing the means of manipulating, interpreting and explaining the structured information.

Whilst this categorisation of a complex and poorly understood aspect of human thinking is simplistic, it does provide us with a framework for assessing and comparing different forms of spatial thinking within archaeology and how they have changed through time. Central to this assessment and comparison are the well-rehearsed archaeological themes of objectivity and subjectivity, scale and understandings of landscape. The main tension to be explored in this paper is that between 'scientific or abstract' space and 'humanised or meaning-laden' space, differences much explored over recent years. With this tension in mind it is possible to expand on the central themes of spatial thinking above in relation to the use of GIS, introducing some of the points to be detailedbelow:

1. Concepts of space: providing the conceptual and analytical framework within which data can be integrated, related and structured into a whole - the issue here is often characterised as the difference between 'space' and 'place', two very different concepts. The former is objective and invariant, a blank container within which human action takes place and can be mapped, measured and analysed with respect to a known co-ordinate system. 'Place' on the other hand is subjective and negotiable, a culturally constituted locale given meaning through the human actions and experiences that happen there (Basso, 1996; Tuan, 2001; Cresswell, 2004), this is relative compared to absolute space. It has long been recognised in geography and archaeology that GIS are typically designed to work with absolute space and are challenged by concepts of place (for an early account see Curry, 1998). Choice of the correct concept of space is critical in any GIS-based analysis as not all maps are based on absolute space - for example, Harry Beck's London Underground Tube map, one of the most iconic maps in the world, is based on relative space. The positions of stations are shown in relation to the London Underground network and do not correspond to their locations above ground (Moran, 2005 p.56). Relative space may also be better suited to the study of phenomena such as Roman trade, with the positions of places defined in relation to the Roman road network rather than their geographic locations (c.f. Orenga and Livarda, 2016). Recent research in the Digital Humanities more widely has highlighted the potential of GIS with regard to the study of the perception of place (e.g. Cooper and Gregory, 2011 and Earley-Spadoni, this volume, for the current situation).

2. Tools of representation: providing the forms within which structured information can be stored, analysed, comprehended and communicated - the issue here is encapsulated within the postmodern 'crisis of representation', how to represent those aspects of human experience that cannot be mapped, measured and analysed objectively (Lock, 2010), a point well made in the introduction to this volume by Howey and Brouwer-Burg who argue for 'unbinding our analysis from the site-driven concept'. GIS data structures based on spatial primitives (point, line, polygon plus cell-based coverages and attribute data) are designed to represent a certain view of the world, one which at face value appears to be at odds with understandings of the world which are not based on empirical objectivism. Maps, and by extension the spatial primitives from which they are comprised, are a codified representation of reality. They are highly stylised and care must be taken to avoid an overly literal interpretation of the symbology used to depict a place or object on a map. Returning to the Tube map, Harry Beck's map distorts 'perceptions of distance, time and location' and in doing so warps the 'boundaries between reality and representation' (Cochrane, 2006 p. 264). 
3. Processes of reasoning: providing the means of manipulating, interpreting and explaining the structured information - the issue here can be characterised as one of methodology, and conversely a lack of it. Here we can differentiate between explicit and implicit methodology. Explicit methodology was integral to the development of objective archaeology, with techniques such as Central Place Theory and Thiessen Polygons based on concepts incorporating measurable distances or costs, techniques that were readily adoptable within the quantitative environments of GIS, see Gillings (this volume) for such a discussion of viewshed methodologies. The qualitative basis of understanding place requires a much less well defined methodology, an alternative approach which can be exemplified by the difference in emphasis between spatial analysis and spatial narrative. Spatial analysis depends heavily on formal analysis to reach an 'output', and thus interpretation, whereas spatial narrative is a much more intuitive and a dialectic relationship between 'data' and interpretation. In spatial analysis the methodology precedes and is separate to the interpretation whereas analysis and interpretation are integrated within a spatial narrative. Implicit methodology is more complex and particularly important within GIS applications, often being incorporated into the general critique of 'technological determinism'. The procedures which underpin GIS operations involve pre-determined algorithms, 'black-box' logics and methodologies hidden from the user but fundamental in influencing the interpretation eventually arrived at, an issue discussed at length by Brouwer Burg (this volume).

These themes provide depth and context to the applications of GIS in archaeology. It is important to recognise that use of GIS in itself does not constitute an advance in spatial thinking. Without a nuanced understanding of concepts of space and detailed justification of processes of reasoning, the role of GIS is reduced to that of a new tool of representation. Having already cast some doubt over the role of methodology, it is important to introduce 'spatial analysis', a poorly defined term that is sometimes conflated with spatial thinking and often assumed to involve precise methodology. Again, there are many definitions of spatial analysis, the one presented here is from an extensive guide to GIS techniques and applications:

'Spatial analysis exists at the interface between the human and the computer, and both play important roles. The concepts that humans use to understand, navigate, and exploit the world around them are mirrored in the concepts of spatial analysis. So ........... will often appear to be following parallel tracks - the track of human intuition on the one hand, with all its vagueness and informality, and the track of the formal, precise world of spatial analysis on the other.' (de Smith et. al., 2015. Our emphasis).

Spatial analysis is subsumed within spatial thinking but as the quote above demonstrates, cannot be divorced from the tension between quantitative and qualitative approaches. To explore this tension further and the links between spatial analysis, spatial thinking and GIS that feed into it, we need to construct an historical context and an understanding of the developing relationships involved. A good place to start is Clarke's influential Spatial Archaeology, in the first chapter of which is presented a thorough explication of spatial theories and methods of the time incorporating four underlying general theories that attempt to move beyond description to explanation: Anthropological, Economic, Social Physics and Statistical (Clarke, 1977). Clarke made a distinction between 'quasi-deductive' non-formal spatial approaches, based on empirical visual interpretation of patterning, and formal modelling, based on quantitative analysis. The most common approaches of the time were formal modelling techniques grounded in economic theory, particularly those from the German geographical tradition (most notably, Central Place Theory and Site Catchment Analysis). Interestingly though, even within this strongly positivist framework Clarke offered a word of caution which is relevant to the tension we are exploring here, 'the underlying theory has been criticized as too ideal in its disregard for non-economic factors and the fact that 'cost' is at least in part a culturally conditioned and relative threshold' (ibid., 19).

In contrast to subsequent developments in archaeological spatial theory, the use of GIS has been seen to encourage retrogressive positivist approaches, a situation that was recognised and criticized early within the 
adoption process (Wheatley, 1993; Gaffney and van Leusen, 1995). This innate conservatism is an acknowledged characteristic of new adopters who tend to use the new technology to do familiar things but in a new way and is apparent within themany applications based on economic modelling, typified by Baena et. al. (1995), who used buffers around Spanish Beaker settlements to explore relationships with flint and salt sources, a form of modified Site Catchment Analysis. However, it is apparent from the earliest literature (Allen et. al., 1990; Gaffney and Stančič, 1991) that the potential for more novel and subjective approaches was identified in the form of modelling movement and visibility, two applications of GIS which were claimed to have the potential to 'humanise' the landscape and have been much developed and discussed since. In his introduction to Interpreting Space, Green talks of 'perceiving landscape' and how 'GIS provides such a means' (Green, 1990, 6), while within the same volume Madry and Crumley (1990) present an example of GIS being used to explore the landscape settings of Iron Age hillforts in France through viewshed analysis and the calculation of least cost pathways. Gaffney and Stančič's more integrated landscape analysis reproduces and develops many quantitative methodologies within an economic framework of analysis but also includes discussion based on integrating movement and visibility using viewsheds and accumulated cost surfaces $(1991,77)$. Not surprisingly both of these early publications predict that the adoption of GIS will revolutionise the theory and practice of spatial archaeology enabling new ways of thinking about spatial relationships.

So what has changed since the early 1990s? There is no doubt that GIS has become de rigueur within archaeology and has indeed revolutionised the collection, integration and management of spatial data within many archaeological contexts. Beyond this obvious impact it is more difficult to assess the influence of GIS on spatial thinking as defined here, particularly its role within interpretation and its influence within theoretical understandings. Thomas $(2004,198)$ argues that the impact is negligible and that digital technologies cannot 'transcend their positivist origins', indeed that GIS 'are embedded in ways of looking and thinking that are distinctly modern, and hence that they are anachronistic when applied to the distant past'. Regardless of this extreme view, the divide between the quantitative analyses seen to be offered by GIS and experiential approaches to landscape is still a focus of concern and discussion as shown by many of the papers published in this volume and elsewhere. It is commonplace for an account of a GIS-based analysis to have an introduction that outlines this long standing debate in one way or another, not least as shown by papers in this volume. This is not necessarily a bad thing as it shows that the debate is still relevant and that new GIS users are theoretically aware and not just mechanically carrying out well established analyses.

The search for a 'middle ground' was thoroughly explored by a conference in 2011 (papers published in the Journal of Archaeological Method and Theory, 2012), during which the two keynote speakers offer detailed histories of the debates and tensions together with insightful suggestions for ways forward. Llobera (2012) argues for a middle ground that can bridge the theory and practice divide through the use of scaffolding models of various types that enable the exploration of potentials rather than attempting to provide 'answers'. This approach is built on by Whitley (this volume) who talks of Middle Range Theory and its updating to include GIS approaches based on models and simulations that can enable interpretation. Countering Llobera, Gillings (2012) offers a different vision in which GIS-using landscape archaeologists should abandon their attempts to incorporate the views of experiential theorists and develop their own theoretical approaches based on innovative developments in applying the technology. Central to this he sees the role of affordance and how it can be used within experiential landscape analysis combining to explore 'experiential affordances' offered by topography and landscape features.

This debate is clouded by various subtle forms of technological determinism as argued by Huggett (2000; 2004) for computer usage more generally in archaeology. His description of 'technological beguilement' and the state of 'technopoly', the seeking of 'authorisation' through technology (ibid. 16), could certainly be argued for GIS which, as he states, put 'technological solutions before archaeological questions' (ibid., 17). One consequence of this is the danger that the use of GIS stifles archaeological creativity to conform to the functionality provided by the technology rather than enabling creativity to flourish. It may be that the popularity of viewshed and movement analyses is as much due to their ease of performing as to their theoretical appropriateness. The 'push button' ease offered by modern GIS software, through menus and default values, hides complex logic and algorithms that many GIS users choose not to engage with. The 
minimal training often available for archaeologists wanting to use GIS results in the casual 'plug and chug' users described by Brouwer Burg (this volume) and leads her to suggest the need for advanced 'power users' to expand the frontiers of GIS-based research. It is perhaps interesting to note that many of the most innovative uses of GIS in archaeology involve programming that goes beyond the standard menus and builtin functionality of commonly used GIS packages, Llobera and Gillings included (McCoy, this volume).

To explore this further we need to consider two complicating factors that feed into many GIS analyses and particularly how they help to create the 'crisis of representation', these are notions of scale and landscape. Although scale is a complex and slippery issue it is something often taken for granted and not well theorised or often discussed in depth in GIS-based archaeology (Lock and Molyneaux, 2006). We can recognise two different forms of scale (Dobres, 2000), 'analytical scale' is the realm of research, the recognition, measurement and analysis of patterns, including operational concepts such as ratio, fraction and spatial resolution. Quite different is 'phenomenological scale' which is the lived scale of being in the world and experiencing embodied interactions in daily life, Ingold's 'dwelling perspective' (Ingold 2000; 2011). A hillfort's rampart and ditch, for example, can be plotted at a scale of 1:500 with a section drawn at 1:20 and be a representation of that monument that impresses, but it is an entirely different experience to an embodied emotional encounter with a two metre high rampart fronted by a four metre deep ditch cut into solid bedrock. This difference reflects the quantitative/qualitative tension described above and has resulted in GIS usage tending to be at the regional scale of mapping and analysis rather than at the human scale of the everyday world, see Howey (this volume). One reason why this is important is because such micro-scale dynamics of daily living contribute to, and create, the macro-scale phenomena which we map and analyse as archaeologists.

The same tension can be seen within understandings of landscape and the practice of 'landscape archaeology', an area of the discipline which has expanded rapidly since the introduction of GIS. The functionality of GIS, particularly the integration of individual data layers, encourages a 'landscape as data' approach whereby discrete types of data such as map, LiDAR, aerial photographic, geophysical and surface survey, are collected and integrated. Understanding and interpretation are often based on an intuitive observation of spatial relationships and patterns that 'emerge' through an inductive process. These may or may not then form the basis for a more formal analysis, perhaps based on the location of specific elements (often 'sites') and their relationships using measures such as proximity or density.

The contrast between this form of landscape study and the subjective, perceiving, humanising, experiential dwelling perspective of Ingold (2011) has been well documented, although it is worth noting that these latter ideas are now embedded within formal definitions of landscape. The European Landscape Convention ${ }^{1}$ focuses on 'perception' and the importance of the 'local' thus 'an area, as perceived by people, whose character is the result of the action and interaction of natural and/or human factors', and UNESCO's concept of World Heritage Sites for the 'intangible' heritage ${ }^{2}$, defined as the 'practices, representations, expressions, knowledge and skills' of people rather than the material world that results from them. This is interesting because it brings the objective/subjective landscape tension into the domain of GIS, for both of these initiatives emanate from Cultural Resource Management where GIS is the de facto tool of choice for the management and display of data although the question remains as to whether the technology can incorporate the understandings as written above.

The Potential of GIS

Both scale and landscape call into question all three elements of spatial thinking within archaeology and its

${ }^{1}$ http://www.coe.int/t/dg4/cultureheritage/heritage/landscape/default en.asp $\left[a c c e s s e d ~ N o v e m b e r ~ 28^{\text {th }}\right.$ 2016]

${ }^{2}$ http://www.unesco.org/culture/ich/en/what-is-intangible-heritage-00003 [accessed November $28^{\text {th }}$ 2016] 
historical development. Processes of reasoning, for example, were at the scale of general cultural processes during the positivist years of the 1960s and 1970s when there was a strong focus on high-level economic modelling. Central Place Theory (CPT), and its associated Thiessen Polygons, established site 'territories', site hierarchies and whole networks of social relationships based on economic interaction (Grant 1986). The economic potential of a site was claimed through its catchment and Site Catchment Analysis (SCA) similarly building into networks of social relationships (Ellison and Harriss 1972). The ultimate of these high-level analyses at the scale of social 'systems' was Systems Theory where the different elements of a 'society' were often worked out through a computer simulation of interacting subsystems and feedback loops (Doran 1970).

A focus on the 'economics' of past societies is, of course, often still central to understanding past social relationships as shown by Hunter and Kosiba (this volume) in their detailed study of Inka agricultural practices and how they changed with the arrival of the Spanish. They argue that GIS tends to 'generalise environmental variables' thus creating rigid views of what was a fluid process in the past. Their sophisticated analysis based mainly on DTM reclassification to understand the 'perceived value' of land during the change from maize to wheat agriculture moves far beyond the simple early models mentioned above. A similar focus on 'resources' as a basis for understanding complex social changes is offered by Jones (this volume). Again the analysis is based on differences within landscape characteristics between the areas occupied by two cultural groups, this time the Piedmont Village Tradition and the more hierarchical Mississippian culture. As with Hunter and Kosiba, the process of reasoning here is much more theoretically informed than with earlier high-level modelling which was more driven by the methodology rather than by the past social context.

Moving beyond the use of formal models in GIS-based archaeology to a scale of reasoning based on personal subjectivity, we need to assess the feasibility of doing so within the digital environment. The importance of 'models' has been argued elsewhere (Lock, 1995), and of course the use of models and modelling was a fundamental part of archaeological reasoning before the use of computers. Interaction between the data model (variables recorded and the structure of data) and the theoretical model (methodologies to be employed) provides the link between an unknowable past and statements made in the present. It is crucial to recognise that using a computer introduces a third link in this chain, the digital model (interplay between conceptual models and data structures) within which both the data and theoretical models have to be represented, if they can't then obviously using a computer will be restrictive. This is increasingly recognised and theorised within the field of archaeological GIS-based modelling, not least by Llobera (2012) as above and Brouwer Burg, Whitley, Howey and Richards-Risetto (this volume), the latter attempting to go beyond 2D modelling and incorporate the third dimension. The question remains, however, what opportunities does the digital model within GIS offer for modelling place rather than space?

To return to basics, GIS offers two ways of thinking about spatial phenomena: 1) the 'discrete-object' view of the world where reality is a surface with identifiable discrete objects positioned across it, each one capable of being measured and assigned attributes, the obvious examples being sites and/or artefacts; 2 ) the 'continuous-field' view of the world models reality through one or more continuous surfaces, each representing variation within a single attribute, perhaps density of artefacts or distance from water. Whilst both views of the world give primacy to accuracy, precision and ultimately reductionism, any modelling of place within GIS must currently be constructed through those values. Place, therefore, becomes a 'location' defined by 'co-ordinates' with 'attributes' which are likely to be quantitative but could be qualitative, although a sensual GIS enabling the inclusion of smells, concepts such as danger, and even images and sounds has been recognised as rare for a long time (Gillings and Goodrick, 1996), and still is.

The world is deconstructed into 'objects' with 'spatial support' in the form of points, lines, polygons and gridcells and if we want a world of multiple properties then we are reliant on the 'layering' structure and georeferencing of GIS. Relationships between objects are formalised and based on the concept of topology, including variations of distance or adjacency and connectivity or containment. Of course this range of structuring and functionality offers many different ways of thinking about and representing spatial phenomena and their relationships, a flexibility that provides GIS with its power albeit within the constraints 
of the technology. Decisions concerning the digital model don't end there as representation requires a series of generalisations and operations - changing perspective and orientation, transforming shapes and sizes, zooming and panning, and the selection, elimination, simplification and aggregation of features - to produce a 'meaningful' image.

As already suggested above, since the earliest applications of GIS within archaeological modelling of visibility and movement, either separately or together, has been seen as a way of humanising dead digital models, avoiding the 'seeing everything from above' detached view of the world and situating the agent within the landscape. Despite the strong whiff of technological determinism that surrounds the early and continuing use of these techniques, such methods can be seen as an attempt at new concepts of space, modelling place and employing new processes of reasoning through explicit methodology. What is often not fully appreciated are the implications of the implicit methodology, the consequences of data and algorithms.

The characteristics of a DEM have fundamental implications for analysis, with resolution or cell size usually singled out as the most important consideration. It is often argued that a low resolution DEM with a cell size of $50 \mathrm{~m}$, which is not unusual at the landscape scale, will impose serious limitations on modelling movement and visibility. In this context, developing technologies are offering much improved resolution and airborne LiDAR, for example, has revolutionised the representation of landscape detail with digital elevation models derived at resolutions of less than $1 \mathrm{~m}$ (Cowley and Opitz 2013). Although rarely considered to be of importance it has long been recognised that different interpolation algorithms will produce very different final models, irrespective of whether a DEM is interpolated from point or contour data or acquired already processed (Kvamme, 1990; Gillings 2015). Little or no consideration, however, has been given to whether algorithms developed for lower resolution digital elevation models are appropriate for the analysis of those with higher resolution.

It is questionable whether these issues matter when what we are trying to model are qualitative and imprecise characteristics. To what extent do we need to be explicit about the quantitative technology that is used to articulate our qualitative thinking and, ultimately, produce the models that we are thinking about? Visibility studies have increased in sophistication from simple binary viewsheds through cumulative viewsheds to distance banded and fuzzy, Higuchi and directional viewsheds (Wheatley and Gillings, 2000; Riggs and Dean, 2007) to visual prominence (Bernardini et. al. 2013), affordance viewsheds (Gillings 2009), hidden viewsheds (Gillings2015) and visualscapes (Llobera 2003). Although the more nuanced representations of visibility offered through these developments have much to offer over the simplistic visible/not visible binary viewshed, any application has to be incorporated within a wider theoretical understanding of landscape and its meaning.

Just as a visibility model is usually dependant on the resolution of the DEM it is based on, so too are movement models but with interesting differences. It is generally argued, as implied above, that a DEM should be of the finest resolution possible as both visibility and movement solutions are calculated and assigned on a cell by cell basis so that smaller units to see or move into represent 'reality' more closely. As we have argued elsewhere (Lock and Pouncett, 2010; Lock et al. 2014), this assumption is questionable for movement as people don't usually wander aimlessly around a landscape based on small-scale topographic decisions but move with intentionality towards a known destination and view things that are more than 5 or $10 \mathrm{~m}$ ahead.

The GIS view of the world which prioritises accuracy and precision (of the DEM), the 'efficiency' of accumulating costs and the perceived 'accuracy' of the algorithm used (Herzog 2014), is at odds with the concept of space (place) we are trying to model, and is counter-intuitive to human decision making concerning movement, as Howey (this volume) also suggests. Ingold $(2000 ; 2011)$ describes movement as 'the unfolding of a field of relations established through immersion within an environmental and social context' mirroring Gibson's (1979) argument that movement and visibility are interlinked and through the 'theory of reversible occlusion a series of unfolding vistas' are the human experience of movement. In an attempt to address these issues directional bias can be built into the friction surfaces used to calculate least- 
cost pathways through the definition of 'corridors of intentionality (Lock and Pouncett 2010; Lock et al. 2014). We have examined whether average slope/cost values assigned to larger 'windows of analysis' represent intentional movement more closely as the walker's gaze and concentration are fixed on the distant destination rather than on the detailed characteristics of the terrain within the next metre or so. Visibility has also been incorporated through the notion of 'cones of visibility' and 'intermediate waypoints', with directional viewsheds used to model the influence of either natural or cultural features that act as attractors or visible targets for movement on the way towards the known final destination.

That visibility and movement studies still form the basis of many more theoretically informed applications of GIS in archaeology is argued in detail by Gillings (this volume) and illustrated by Richards-Rissetto's analysis of Mayan "acts of seeing" involving moving through 3-dimensional architecture and relating what is seen to social status and identity (this volume). Equally innovative in terms of relating visibility and movement to evolving theoretical approaches is Gustas and Supernant's (2017) study of water-based movement along the northwest coast of North America in the Holocene period. This development of so called 'marine least cost paths' is based on the argument that traditional measures of cost are ineffective on water (see also de Roo 2014 and Slayton n.d.). A new range of costs broken down into environmental, physiological and cultural are proposed and used.

Visibility and movement fit within the framework of spatial thinking and show how GIS can work towards concepts of space, using tools of representation and processes of reasoning albeit within technological constraints. But what happens if the actual framework is considered to be inappropriate as with one branch of spatial thinking where representation is considered not possible or desirable (Lock, 2010). Thrift (1996) has put forward 'non-representational' theory which is based on 'practice' theory and sees the participation in embedded cultural practices, so that the 'absorbed coping' and 'engaged agency', give life meaning. There are, of course, many different strands to the 'inhabitation as practice' approach to landscape and if collectively they indicate a move away from representation this offers a major challenge to archaeological GIS. Ingold's (1993) notion of 'taskscape' rather than landscape gives primacy to practice in the creation of cultural landscapes; an approach which reactivates the idea that 'affordances', or what the material world enables us to do, as being central to human behaviour. An attempt to apply this through GIS is Trifkovic's DEM-based analysis of prehistoric food resources and exploitation practices in the Iron Gates Gorge, Serbia (2006). This is a novel approach which shows the potential of GIS and emphasises the importance of scale, using personal biographies to show how individuals and groups construct their own interactions with the landscape.

Non-representational theory is obviously a serious challenge to GIS, one which is increased by subsequent developments such as 'more-than-representational theory' (Lorimer, 2005) and the idea of the 'deep map' (Pearson, 2006; Bodenhamer et. al. 2015). This move beyond representational theory attempts to work with a range of experiences and information and is perhaps best summarised by the following quote:

'The focus falls on how life takes shape and gains expression in shared experiences, everyday routines, fleeting encounters, embodied movements, precognitive triggers, practical skills, affective intensities, enduring urges, unexceptional interactions and sensuous dispositions. Attention to these kinds of expression, it is contended, offers an escape from the established academic habit of striving to uncover meanings and values that apparently await our discovery, interpretation, judgement and ultimate representation' (Lorimer, 2005, 84).

According to Lorimer, landscape, or rather being human as the creator of landscape, is in a constant flux and state of becoming and not something that can be objectively represented in a detached way as in GIS models. An intriguing example of this approach is Pearson's (2006) 'In comes I' in which he uses performance 'as an alternative medium of representation to cartography'. Pearson enacts a sense of place through the materiality of the surrounds, historical depth, oral histories, archaeology, geology and a whole range of other forms of understanding at the three different scales of village, neighbourhood and region, so that his resulting 'deep map' is a reworked version of thick description. As a process of reasoning this draws into 
focus the tension between models and narrative, GIS models as the essence of academic endeavour to uncover meaning waiting to be discovered and narrative as the emergent complexities within story telling. Again this highlights the tension between the accuracy and precision which enables GIS to perform spatial analysis and the uncertainty and ambiguity that is a celebrated part of writings on place.

There has been a growing critique of GIS for several years now inspired by the critical mapping movement of geography (Shuurman 1999) and increasingly applied to archaeology, for an early example see Hacıgüzeller (2012), and for the current diversity of approaches Hacıgüzeller et. al. (in press). Here maps are seen as a reflexive process and not a product, as an ongoing mode of engagement, as unstable, fragile and temporary understandings, as a conversation and not a final statement. These contrast sharply with the 'GIS view of the world' and challenge all three elements of spatial thinking that underlie GIS.

It is important to acknowledge that there is perhaps a semantic issue here concerning what we actually mean by 'GIS', an issue being forced by the rapid development of desktop and web-based mapping software. In the early days of the technology, software had to have the facilities of data input, data storage and retrieval, data manipulation and analysis, and data reporting, and the ability to carry out topological analysis and create secondary data layers to be considered a Geographic Information System (Marble, 1990). As the initial zeal of early adopters has faded the boundaries between GIS and other spatial software has become increasingly blurred, as maps and spatial data become increasingly available within the public domain and less the reserve of academics and professional interest groups. It is no longer clear whether it matters that Marble's strict definition is adhered to or whether we are happy to embrace 'geo-spatial' and 'geo-visualization' as second generational understandings of the same issues.

These points are brought into sharp focus by new and rapidly developing web applications but also by the shift in developer communities to include mass collaboration. The potential of Web 2.0 technologies for the humanities, here including archaeology, have been shown by Harris et. al. (2010) and the implications for spatial thinking are profound. Using concepts such as the geospatial semantic web, neo-geography and Pareto GIS, they outline the core of what constitutes a 'humanities GIS'. This is structured around 'authoritative' (formally provided) as well as 'asserted' information in the form of Volunteered Geographic Information (VGI) and User Generated Content (UGC) (Goodchild, 2009), part of the 'we-think' (rather than 'I Think') philosophy (Leadbeater, 2008). Central to this is the idea that from the collective intelligence a form of 'truth' emerges, the wiki- approach given spatial form through applications like wiki-mapia ${ }^{3}$.

\section{Conclusion}

Returning to the central theme of this paper, to what extent does GIS work with or against spatial thinking in archaeology, we can draw some general conclusions. The 'informal' GIS offered by the new Web 2.0 technologies and the traditional 'formal' GIS seem to equate with Clarke's informal and formal spatial analyses. The 'informal' approaches offer opportunities for extending concepts of space, new tools of representation and breaks down some of the barriers within processes of reasoning. As argued above, all three of these elements are somewhat compromised within traditional formal approaches. While GIS are essential tools for much of the data integration, manipulation and analysis that comprise contemporary spatial archaeology, there is a wellrecognised mismatch between humanist understandings of space/place and what GIS can model. It is essential that as a discipline we avoid the state of technopoly described above and develop a critical engagement where spatial theory is central to the applications of GIS in archaeology rather than the current status quo where applications are all too often driven by the opportunistic pushbutton functionality offered by the technology. This will require a move away from the historical perception of computers being merely tools that can be applied to the full range of activities in

${ }^{3}$ http://wikimapia.org/ [accessed September $21^{\text {st }} 2016$ ] 
archaeology, even a suite of tools as suggested by Martlew as long ago as 1984 that would provide an 'Archaeological Information System'. Goodchild (1992) coined the term GISc(ience) to encapsulate the idea that GIS is capable of moving beyond the 'merely a tool' critique to incorporate various disciplinary needs, theoretical frameworks and analytical approaches. An argument that has subsequently been recognized within archaeology, for example Conolly and Lake (2006; 6), Harris et. al. (2010) and (Llobera 2010) who see Archaeological GISc(ience) or Archaeological Information Science (AISci) offering a deeper understanding, being more challenging and intellectually rewarding than a focus on GIS as a 'spatial toolbox'. Whilst the debate over 'Is GIScience a science?' continues to run (see Reitsma 2012), its emphasis on the fundamental principles which underpin the use of Geographic Information Systems has unquestionably had positive benefits for disciplines like archaeology. Concepts such as atomic GI (Goodchild 2003, Zhang and Goodchild 2002) - the concept that geographic information is comprised of tuples of atoms of the form $\{x, z, t\}$, where $x$ is a set of places, $z$ is a set of attributes and $t$ is a set of times - have huge implications not just for the development of spatial technologies but for the kinds of research questions that those technologies can be applied to. As suggested by Gillings (2012), and supported here, it is only through GIS-using archaeologists defining their own theoretical framework/questions/agenda that GIS can provide a full and rich answer to spatial thinking in archaeology.

References

Allen, K. M. S., Green, S. W. and Zubrow, E. B. W., (Eds). 1990. Interpreting Space: GIS and Archaeology. London, Taylor and Francis.

Baena, J., Blasco, C., Recuero, V. 1995, The spatial analysis of Bell Beaker sites in the Madrid region of Spain, in G. Lock and Z. Stančič (eds), Archaeology and Geographic Information Systems: a European Perspective, London, Taylor and Francis, 101-16.

Basso, K.H. 1996. Wisdom sits in places. Landscape and language among the Western Apache. Albuquerque: University of New Mexico Press.

Bernardini, W., Barnash, A., Kumler, M. and Wong, M. 2013. Quantifying Visual Prominence in Social Landscapes. Journal of Archaeological Science, 40 (11): 3946-54. doi:10.1016/j.jas.2013.05.019.

Bodenhamer, D., Corrigan, J. and Harris, T. (eds). 2015. Deep maps and spatial narratives. Bloomington: Spatial Humanities, Indiana University Press.

Clarke, D.L. 1977. Spatial information in archaeology, in Spatial Archaeology, D. L. Clarke (ed). London: Academic Press, 1-32.

Cochrane, A. 2006. The Simulacra and Simulations of Irish Neolithic Passage Tombs, in Images,

Representations and Heritage: Moving beyond Modern Approaches to Archaeology, I. Russell (ed). Boston: Springer, 247-78.

Cooper, D. and Gregory, I. 2011. Mapping the English Lake District: A Literary GIS, Transactions of the Institute of British Geographers, 36(1), 89-108.

Cowley, D. and Opitz, R. eds. 2013. Interpreting Archaeological Topography: Airborne Laser Scanning, 3D Data and Ground Visualisation. Oxford: Oxbow.

Cresswell, T. 2004. Place. A short introduction. Oxford: Blackwell Publishing.

Curry, M.R. 1998. Digital Places. Living with Geographic Information Technologies. London: Routledge. 
De Roo, T. 2014. The Viking Sea from A to B: Charting the nautical routes from Scandinavia to the British Isles in the early Viking period. Unpublished PhD: University of Cambridge.

de Smith, M., Goodchild, M. and Longley, P. 2015. Geospatial Analysis - a comprehensive guide. $3^{\text {rd }}$ edition. Available online at http://www.spatialanalysisonline.com/output/. 5th edition. [accessed October 3rd 2016].

Devereux, B.J., Amable, G.S., Crow, P. and Cliff, A.D. 2005. The potential of airborne LiDAR for detection of archaeological features under woodland canopy, Antiquity, 79, 648-60.

Dobres, M-A. 2000. Technology and Social Agency. Oxford: Blackwell.

Doran J.E. 1970, Systems theory, computer simulations and archaeology, World Archaeology, 1, 35, 289-98.

Ellison A., Harriss J. 1972, Settlement and land use in the prehistory and early history of southern England: a study based on locational models, in D. L. Clarke, (ed), Models in archaeology, London, Methuen, 911-962.

Gaffney, V. and Stančič, Z. 1991. GIS approaches to regional analysis: A case study of the island of Hvar. Ljubljana, University of Ljubljana, Znanstveni Inštitut Filozofske Fakultete.

Gaffney V., van Leusen P.M. 1995, GIS, environmental determinism and archaeology, in G. Lock, Z. Stančič (eds), Archaeology and Geographic Information Systems: a European Perspective, London, Taylor and Francis, 367-382.

Gibson, J.J. 1979. The ecological approach to visual perception. Boston: Houghton Mifflin.

Gillings, M. 2009. Visual Affordance, Landscape, and the Megaliths of Alderney. Oxford Journal of Archaeology 28 (4), 335-56.

Gillings, M. 2012. Landscape Phenomenology, GIS and the Role of Affordance. Journal of Archaeological Method and Theory, 19, 601-611.

Gillings, M. 2015. Mapping Invisibility: GIS Approaches to the Analysis of Hiding and Seclusion'. Journal of Archaeological Science 62 (October), 1-14. doi:10.1016/j.jas.2015.06.015.

Gillings, M. and Goodrick, G. 1996. Sensuous and reflexive GIS: exploring visualisation and VRML. Internet Archaeology, 1. Available online at http://intarch.ac.uk/journal/issue1/gillings index.html

Goodchild, M.F. 1992. Geographical information science. International Journal of GIS, 6, 1, 1-45.

Goodchild, M. 2009. Virtual geographic environments as collective constructions, in Lin, H. and Baty, M. (eds) Virtual Geographic Environments. Beijing: Science Press, 15-24.

Goodchild, M., 2003. The nature and value of Geographic Information, in: Duckham, M., Goodchild, M., Worboys, M. (Eds.), Foundations of Geographic Information Science. Taylor \& Francis, London, 18-30.

Grant E. (ed) 1986, Central Places, Archaeology and History. Sheffield, Department of Archaeology and Prehistory, University of Sheffield.

Green, S.W. 1990. Approaching archaeological space: an introduction to the volume, in Allen, K. M. S., Green, S. W. and Zubrow, E. B. W., (Eds), Interpreting Space: GIS and Archaeology. London, Taylor and Francis, 3-8.

Gustas, R. and Supernant, K. 2017. Least cost path analysis of early maritime movement on the Pacific North 
West coast. Journal of Archaeological Science, 78, 40-56.

Hacıgüzeller, P. (2012). GIS, critique, representation and beyond. Journal of Social Archaeology, 2, 245-263.

Hacıgüzeller, P., Gillings, M. and Lock, G. in press. Re-mapping archaeology: critical perspectives, alternative mappings. New York: Springer.

Harris, T.M., Corrigan, J. and Bodenhamer, D.J. 2010. Challenges for the spatial Humanities: towards a research agenda, in Bodenhamer, D.J., Corrigan, J. and Harris, T.M. (eds) The Spatial Humanities. GIS and the future of Humanities scholarship. Bloomington: Indiana University Press, 167-76.

Herzog, I. 2014. Least-Cost Paths - Some Methodological Issues. Internet Archaeology, no. 36. doi:10.11141/ia.36.5.

Huggett, J. 2000. Computers and archaeological culture change. In Lock, G. and Brown, K. (eds) On the theory and practice of archaeological computing. Oxford: Oxford University Committee for Archaeology, Monograph No. 51, 5-22.

Huggett, J. 2004. Archaeology and the New Technological Fetishism, Archeologia e Calcolatori, 15: 81-92.

Ingold, T. 1993. The temporality of landscape. World Archaeology, 25, 152-71.

Ingold, T. 2000. The perception of the environment: essays on livelihood, dwelling and skill. London: Routledge.

Ingold, T. 2011. Being alive. Essays on movement, knowledge and description. London: Routledge.

Kvamme, K. 1990. GIS Algorithms and their Effects on Regional Archaeological Analysis, in K. M. S. Allen, S. W. Green, and E. B. W. Zubrow eds., Interpreting Space: GIS and Archaeology. London: Taylor and Francis, 112126.

Leadbeater, C. 2008. We Think: mass innovation, not mass production. London: Profile.

Llobera, M. 2003. Extending GIS-Based Visual Analysis: The Concept of Visualscapes. International Journal of Geographical Information Science 17 (1): 25-48. doi:10.1080/713811741.

Llobera, M. 2010. Archaeological Visualization: Towards an Archaeological Information Science (AISc). Journal of Archaeological Method and Theory, 18(3), 193-223 DOI 10.1007/s10816-010-9098

Llobera, M. 2012. Life on a Pixel: Challenges in the Development of Digital Methods Within an "Interpretive" Landscape Archaeology Framework. Journal of Archaeological Method and Theory, 19, 495-509.

Lock G. 1995, Archaeological computing, archaeological theory and moves towards contextualism, in Huggett, J., Ryan, N. (eds), CAA94. Computer Applications and Quantitative Methods in Archaeology 1994, Oxford: British Archaeological Reports International Series 600, 13-18.

Lock, G. 2010. Representations of space and place in the Humanities, in Bodenhamer, D.J., Corrigan, J. and Harris, T.M. (eds), The Spatial Humanities. GIS and the future of Humanities scholarship. Bloomington: Indiana University Press, 89-108.

Lock, G. and Molyneaux, B. (eds). 2006. Confronting Scale in Archaeology: issues of theory and practice. New York: Springer. 
Lock, G. and Pouncett, J. 2010. Walking the Ridgeway revisited: The methodological and theoretical implications of scale dependency for the derivation of slope and the calculation of least-cost pathways. In Frischer, B. Webb Crawford, J. and Koller, D. (eds) CAA 2009 Making History Interactive. Proceedings of the 37th CAA Conference, Williamsburg, Virginia. Oxford: Archaeopress, 191-202.

Lock, G., Kormann, M. and Pouncett, J. 2014. Visibility and movement: towards a GIS-based integrated approach. In Polla, S. and Verhagen, P. (eds) Computational approaches to the study of movement in Archaeology. Berlin: De Gruyter. TOPOI. Berlin Studies of the Ancient World, Volume 23, 23-42.

Lorimer, H. 2005. Cultural geography: the busyness of being 'more than representational'. Progress in Human Geography, 29:1, 83-94.

Madry, S.L.H. and Crumley, C.L. 1990. An application of remote sensing and GIS in a regional archaeological settlement pattern analysis: the Arroux River valley, Burgundy, France, in Allen, K. M. S., Green, S. W. and Zubrow, E. B. W., (Eds), Interpreting Space: GIS and Archaeology. London, Taylor and Francis, 364-80.

Marble, D.F. 1990. Geographic Information Systems: an overview, in D. J. Pequeut and D. F. Marble (eds.), Introductory readings in Geographic Information Systems. London: Taylor and Francis, 8- 39.

Martlew, R. 1984. Information Systems in Archaeology. Gloucester: Alan Sutton Publishing.

Moran, J. 2005 Reading the everyday, Routledge, London.

Orengo, H. and Livarda, A. 2016. 'The seeds of commerce: a network analysis-based approach to the Romano-British transport system'. Journal of Archaeological Science, 66, 21-35.

Pearson, M. 2006. In comes I: performance, memory and landscape. Exeter: University of Exeter Press.

Reitsma, F., 2013. Revisiting the "Is GIScience a science?" debate (or quite possibly scientific gerrymandering). International Journal of Geographical Information Science 27, 211-221. doi:10.1080/13658816.2012.674529

Riggs, P.D. and Dean, D.J. 2007. Assessing the level of visibility of cultural objects in past landscapes. Journal of Archaeological Science, 28, 1005-14.

Schuurman, N. 1999. Critical GIS: Theorizing an Emerging Science, Cartographica: The International Journal for Geographic Information and Geovisualization. 36(4): Monograph 53.

Slayton, E. n.d. Seascape Corridors: How modelling routes through the sea can illuminate early island culture. Unpublished PhD thesis: University of Leiden (to be completed in 2017).

Thomas, J. 2004. Archaeology and modernity. London: Routledge.

Thrift, N. 1996. Spatial formations. London: Sage.

Tilley, C. 1994. The phenomenology of landscape. Places, paths and monuments. Oxford: Berg.

Trifkovic, V. 2006. Persons and landscapes: shifting scales of landscape archaeology", in G. Lock and B. Molyneaux (eds.), . Confronting Scale in Archaeology: issues of theory and practice. New York: Springer, 25771.

Tuan, Y-F. 2001 (1977). Space and Place. The perspective of experience. (2nd Edition). Minnesota: University 
of Minnesota Press.

US National Academies, 2006. Learning to Think Spatially: GIS as a support system in the K-12 curriculum. Washington: The National Academies Press. Available online at http://books.nap.edu/openbook.php?record id=11019\&page=1 [accessed January 10th 2011]

Wheatley, D. 1993. Going over old ground: GIS, archaeological theory and the act of perception. In Computing the Past: Computer Applications and Quantitative Methods in Archaeology CAA92. T. Madsen and I. Scollar, (Eds). Aarhus, Aarhus University press, 133-38.

Wheatley, D. and Gillings, M. 2000. Vision, perception and GIS: developing enriched approaches to the study of archaeological visibility, in G. Lock (ed)., Beyond the map: archaeology and spatial technologies.

Amsterdam: IOS Press, 1-27.

Zhang, J., Goodchild, M.F., 2002. Uncertainty in geographical information, Research monographs in geographic information systems. Taylor \& Francis, London. 